$\Rightarrow$ ANTICOAGULATION THERAPY

\title{
Appropriate dosing of apixaban
}

In the ARISTOTLE trial of apixaban versus warfarin for stroke prevention in patients with atrial fibrillation, those with two or more dose-reduction criteria (aged $\geq 80$ years, weight $\leq 60 \mathrm{~kg}$, creatinine level $\geq 1.5 \mathrm{mg} / \mathrm{dl}$ ) received $2.5 \mathrm{mg}$ of apixaban twice daily, instead of the full dose of $5 \mathrm{mg}$ of apixaban twice daily. A secondary analysis of the trial data has now been performed to determine the safety and efficacy of apixaban $5 \mathrm{mg}$ twice daily in patients with only one dose-reduction criterion.

Of the 17,370 patients randomly assigned to apixaban $5 \mathrm{mg}$ or warfarin in ARISTOTLE, $76.9 \%$ met no dose-reduction criteria, $22.8 \%$ met one dose-reduction criterion, and $0.3 \%$ met two dose-reduction criteria. The 3,966 patients with one dose-reduction criterion had higher rates of stroke or systolic embolism (HR 1.47) and major bleeding (HR 1.89) compared with those with no dosereduction criteria. Compared with warfarin, the $5 \mathrm{mg}$ dose of apixaban showed a similar benefit on stroke and systemic embolism in patients with one dose-reduction criterion (HR 0.94) and those with no dose-reduction criteria (HR $0.77 ; P=0.36$ for interaction). The $5 \mathrm{mg}$ dose of apixaban compared with warfarin also showed a similarly lower rate of major bleeding in patients with one dosereduction criterion (HR 0.68) and those with no dose-reduction criteria (HR 0.72; $P=0.71$ for interaction).

"Patients should be treated with the effective doses as studied, because using the reduced $2.5 \mathrm{mg}$ twice daily dose of apixaban in this population [of patients with one dosereduction criterion] could result in preventable strokes," summarize the investigators. In an accompanying Editorial, Jeffrey Weitz and John Eikelboom concur: "Education is urgently needed to translate this information into practice because the inappropriate use of the lower dose of apixaban may place patients at risk for stroke."

Gregory B. Lim

ORIGINAL ARTICLE Alexander, J. H. et al. Apixaban $5 \mathrm{mg}$ twice daily and clinical outcomes in patients with atrial fibrillation and advanced age, low body weight, or high creatinine: a secondary analysis of a randomized clinical trial.JAMA Cardiol. http://dx.doi.org/10.1001/jamacardio.2016.1829 (2016) 